\title{
El acceso al agua como factor de identificación de problemas de desarrollo agrario sostenible en el territorio del Alto Guadiana
}

\section{The access to the water as factor of identification of problems of sustainable agrarian development in the High Guadiana territory}

\author{
Ángel Raúl Ruiz Pulpón*
}

\section{INTRODUCCIÓN}

La cuenca del río Guadiana en Castilla-La Mancha se localiza en la parte más céntrica de la región (figura 1). Se trata de un territorio con una altitud media que supera los 600 metros, unas temperaturas que oscilan entre los 14 y los 16 grados, y con unos niveles de precipitaciones que fluctúan entre los 300 y los 400 mm al año (Juárez, 1979). El conjunto está caracterizado por la presencia del río Guadiana que da lugar a una tipología fluvial basada en su irregularidad y la enorme interdependencia de estos cursos superficiales con los subterráneos (Cruces de Abia, 1998).

La parte alta de la cuenca del Guadiana cuenta con la mayor conflictividad ecológica, económica y social que atañe al uso del agua, derivada de la expansión de los regadíos en la década de los setenta y la consecuente sobreexplotación de sus acuíferos subterráneos. Los factores que explicaron la difusión del mismo se basaron en la existencia de una legislación de aguas subterráneas obsoleta, la identificación del regadío como condición

* Departamento de Geografía y Ordenación del Territorio. Facultad de Letras. Universidad de Castilla-La Mancha. 
de modernidad (Arroyo, 1988, pág. 144), el fácil acceso de los particulares a la tecnología de riego (García, 1989, pág. 128), el apoyo de la administración (Ureña, 1997, pág. 657), y en general, la falta de una visión integral sobre el ciclo del agua, basada fundamentalmente en el desconocimiento de las interconexiones entre los acuíferos y los ríos (López Sanz, 1997; Viladomiú y Rosell, 1997; Llamas, 1996, pág. 66-69).

El ritmo de extracciones fue muy considerable en los años setenta y ochenta, en consonancia con el crecimiento de superficies de una serie de cultivos muy exigentes en agua, como la remolacha azucarera, el maíz o la alfalfa, que en esos momentos gozaban de una buena coyuntura de mercado. El aumento del consumo de agua ocasionó que se afectara, necesariamente, a los espacios naturales interrelacionados con los acuíferos. Las cerca de 25.000 ha que formaban parte de la Reserva Mundial de la Biosfera "La Mancha húmeda", entre las que se incluían el Parque Nacional de las Tablas de Daimiel, o el Parque Natural de las Lagunas de Ruidera, se hallaron ante un grave problema de desorden ecológico.

\section{Figura 1. localización de la cuenca del Guadiana en Castilla-La Mancha}

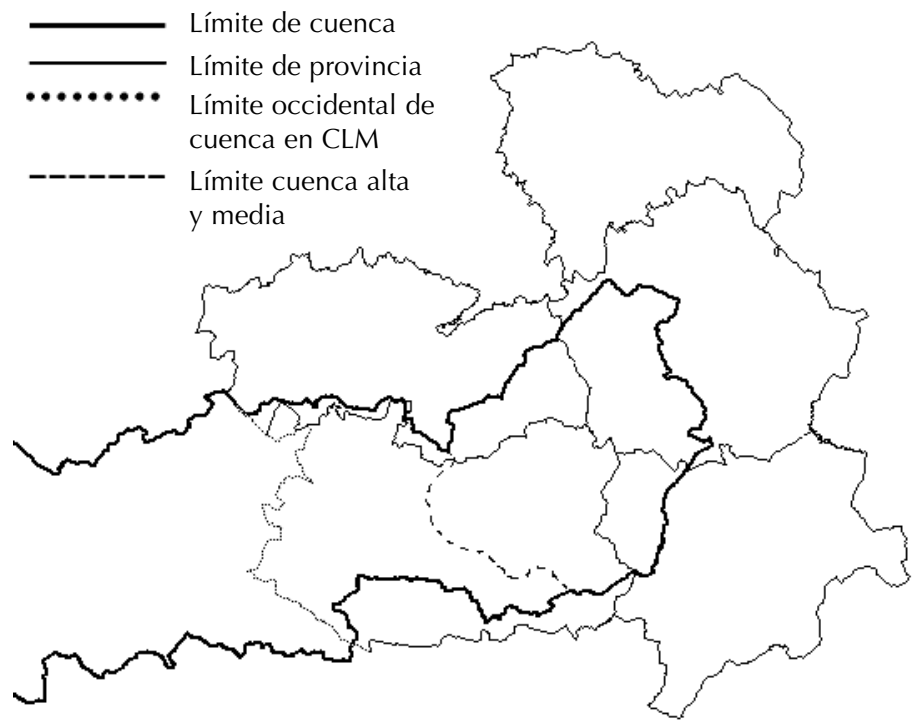

Fuente: Área de Informática de la C.H.G.; elaboración propia.

En contraste con la pérdida del patrimonio ambiental, desde una perspectiva económica, el regadío ha traído consigo una mejora sustancial de 
las rentas obtenidas del campo, debido al aumento de la productividad y a la coexistencia de pagos subsidiados de las administraciones. La transformación privada se realizó bajo el principio de maximizar la inversión efectuada, utilizando un bien común de acceso abierto a todos los usuarios sin plantearse posibles repercusiones sobre la conservación futura de esos recursos (Hernández, 1998). A esta cuestión se le unen otros problemas o estrangulamientos, como que los derechos reconocidos sobre el uso del agua superan en un $200 \%$ los recursos renovables del acuífero de la Mancha Occidental, la complejidad del proceso de inscripción de derechos tras la Ley de Aguas de 1985, la falta de coordinación entre las administraciones que tienen competencias en agua y en agricultura, y en general, la ausencia de una perspectiva integral o multidisciplinar del problema en el proceso de toma de decisiones.

Entre las principales dificultades del modelo agrario establecido destaca la injusticia en el reparto social y económico del agua. La acumulación de derechos de agua ha dado ocasión a una respuesta social y económica distinta ante los preceptos administrativos y legales que regulaban el medio hídrico. El cumplimiento de los regímenes de explotación, el agotamiento de los pozos, los efectos de la sequía, o la imposibilidad, tras la declaración provisional de sobreexplotación de 1987, de realizar nuevas perforaciones, han incidido de distinta manera entre los regantes. La complejidad del proceso se fortalece por la pervivencia de dos modelos de explotación antagónicos: el familiar y el empresarial. Las primeras son las más sensibles ante las disposiciones del organismo de cuenca o los ciclos de sequía, mientras que las segundas se constituyen como negocios agrarios que son los que ostentan las concesiones de agua más importantes.

\section{OBJETIVOS, METODOLOGÍA Y FUENTES}

El objetivo fundamental es la identificación de los desequilibrios estructurales que se plantean por el acceso al agua en la cuenca del Guadiana en Castilla-La Mancha, advirtiendo del grado de significación social y económica que puedan adquirir los grandes propietarios de la misma en sus respectivos municipios. Las diferencias se confirman a partir del estudio de la estructura de las captaciones de regadío resultante tras la aplicación de la Ley de Aguas de 1985, una vez finalizado el proceso de inscripción que requería la nueva situación administrativa. El conocimiento de esas desigualdades puede servirnos para reflexionar sobre la necesidad que tiene la 
regulación y la reordenación de las concesiones de agua de cara a la resolución del problema económico, social y ambiental que ha perdurado en los últimos treinta años en dicho territorio.

El objetivo propuesto se concreta en dos fases:

1. Estudio de las captaciones reconocidas tras la puesta en funcionamiento de la Ley de Aguas de 1985. La información de referencia será el número de pozos y la superficie regada por cada uno, lo que nos permitirá obtener un primer acercamiento a los espacios con mayor capacidad hídrica. La fuente de información ha sido el Inventario de captaciones de la Confederación Hidrográfica del Guadiana de 1989 que fue el primer intento de catalogación de los pozos existentes. Figuran gran parte de las captaciones registradas tras el proceso de inscripción de derechos que establecía la Ley de Aguas de 1985, tanto de las solicitudes que demostraron que existían antes de ese año, como aquellas que se reconocieron en los tres años de prórroga establecidos por el organismo de cuenca para que el agricultor justificase su derecho a la concesión. Se muestra el municipio, el paraje, las coordenadas del pozo, la superficie regada por captación, el caudal en litros por segundo, y si su uso era para fines de abastecimiento, industrial, ganadero o agrícola. El Inventario podría señalar el estado aproximado de los derechos de agua inscritos en el Catálogo y en el Registro de aguas privadas de la Confederación, ya que no recogía información de cual era el destino del agua y el régimen de explotación para cada uno (Hernández, 1998). Otras limitaciones que muestra es su referencia exclusiva a la superficie que está dedicada al riego de herbáceo; la posible falta de adecuación a la realidad, ya que no es capaz de determinar el estado real de los pozos, es decir, si estaban secos, si regaban más de la superficie declarada, o si se reprofundizaron; y la divergencia del número de hectáreas de regadío declaradas si comparamos los datos de este inventario con el de las Superficies de los Cultivos Agrícolas de las Cámaras Agrarias Locales para el mismo año. La explicación viene definida por el hecho de que la declaración de la cédula catastral no supone que se tenga derecho a la concesión administrativa del organismo de cuenca, acentuándose el tradicional desfase de los datos de las superficies regadas entre las Administraciones (López Sanz, 1997; Serna y Gaviria, 1995).

2. En segundo lugar, y partiendo de la hipótesis de que existe un claro desequilibrio en la estructura de las captaciones, se justifica la necesidad de un comentario de las peculiaridades sociales y económicas de 
los propietarios que superen las 50 ha regadas mediante su identificación en el Catastro de Rústica y para aquellos municipios más significativos. De esta forma se pretende un acercamiento a la realidad de los propietarios de esos pozos porque no hay forma de averiguar a quiénes pertenecen en el Inventario. En el establecimiento del límite de los propietarios se ha prescindido del valor catastral porque algunos de los titulares que sobresalían lo hacían con explotaciones no dedicadas al regadío. A continuación se ha evaluado el peso específico de estos agentes respecto al resto de titulares y se ofrece una caracterización social y económica a través del estudio de su condición jurídica y de su lugar de residencia.

La fuente que hemos utilizado ha sido el Libro de Cédulas Catastrales del Catastro de Rústica del año 2000. Junto a la accesibilidad, cuenta con un considerable grado de desagregación a escala municipal. Entre la información figura el nombre y los apellidos del titular, el topónimo del paraje al que pertenece la explotación, los polígonos y las parcelas de la misma, su extensión, el uso del suelo identificado por un código, el valor catastral y el domicilio fiscal. Entre los principales impedimentos destaca la limitación territorial, la profundidad temporal, y la identificación no pormenorizada de los usos del suelo.

\section{ESTADO DE LA CUESTIÓN: EL PAPEL DE LOS FACTORES LEGISLATIVOS EN EL RECONOCIMIENTO DE DERECHOS}

Los desequilibrios en el uso privado del agua se concretaron una vez puesta en marcha la Ley de Aguas de 1985. La Ley declaraba como bien de dominio público las aguas subterráneas, estableciendo una disposición transitoria donde se reconocía el uso privado de aquellas captaciones que demostrasen que existían con anterioridad a la puesta en marcha de la misma.

Hasta llegar a este momento, la configuración de la estructura de la propiedad actual asienta sus orígenes en el proceso desamortizador del siglo XIX, en un contexto donde la agricultura de regadío tenía un aprovechamiento de tipo tradicional, caracterizada por la escasa importancia de sus superficies, la infrautilización de los recursos, y la deficiencia de las técnicas de riego (Hervás, 1991, págs. 177-248; Arroyo, 1998, pág. 122). La desamortización supuso la adquisición de grandes lotes de tierra por parte de la nobleza y de la burguesía local en sus respectivas comarcas agrarias. Las propiedades adquiridas se mantuvieron o se fueron vendiendo a otros 
miembros de la burguesía provincial a lo largo del siglo XX, en un proceso similar al acaecido en gran parte de Castilla-La Mancha (Mata, 1988). Muchas de estas explotaciones se vincularon con la adquisición de terrenos alejados de los núcleos de población. La distancia, la mayor profundidad a la que aparecía el agua de los pozos, y en ocasiones, las dificultades del suelo, actuaron como circunstancias para que estos espacios no fueran, en principio, de especial atractivo para la compra por parte de los agricultores locales. Tras la promulgación de la Ley de 17 de julio de 1956 "sobre colonización y saneamiento de las tierras pantanosas que se extienden inmediatas a los márgenes del río Guadiana, Cigüela, Záncara y afluentes", fueron los propietarios que tenían sus terrazgos en zonas de vega o de llanuras de inundación de los ríos los principales beneficiarios (Plaza y Ruiz, 2002).

A partir de los años sesenta hubo un cambio de iniciativa en la difusión de los regadíos. La necesidad, por parte del Estado central, de establecer un trasvase de agua desde la cabecera del Tajo hasta el sureste español contribuyó a mermar, aún más, las posibilidades de desarrollo económico de Castilla-La Mancha (Pillet, 2001, pág. 54). Dicha actuación, junto a la difusión de una serie de estudios por parte del IGME que revelaban la importante capacidad hídrica que la cuenca alta albergaba en su subsuelo (Velasco, 2005), motivaron que durante la década de los setenta apareciera como principal impulsor de la expansión del regadío la iniciativa privada, que utilizó los progresos de la tecnología del riego para la obtención de agua de origen subterráneo (García, 1989, pág. 128), iniciando, por consiguiente, una nueva fase agraria en gran parte de estos municipios (Pillet, 2001).

Los factores que favorecieron la expansión de las superficies regadas se vieron reforzados por el marco legal existente. La Ley de Aguas de 1879 reconocía las aguas subterráneas como bien de dominio privado, perteneciendo legítimamente a quien las alumbrase. Se podía elevar toda el agua que se quisiera a través de pozos domésticos (ordinarios) o artesianos (de mayor envergadura), siempre que no se interfiriera en las corrientes naturales subterráneas; para ello, se fijaban las distancias mínimas entre pozos: quince metros en el campo para los domésticos, y hasta 100 metros de los considerados de mayor envergadura (Fayás, 2000). El uso doméstico al que mayormente era destinado, la falta de tecnología adecuada, y un modelo agrario dominado por el secano, se consideran como los elementos que demostraron que no era necesaria ninguna disposición sobre la gestión del agua que no fuera para aquella en la que los vecinos se la pudieran repartir. Lo más sorprendente es que estas disposiciones se mantuvieron hasta 
1985, evidenciando la falta de adecuación o de vacío legal respecto a los problemas ambientales asociados al uso del agua subterránea.

La llegada de la Ley 29/1985 de Aguas estableció que las aguas subterráneas se declararan como de dominio público hidráulico (artículo 2), en un contexto donde el conocimiento del ciclo hidrológico y la existencia de problemas de gestión y de contaminación eran ya evidentes. La declaración supuso que los antiguos aprovechamientos basados en la Ley de 1879 se debían adecuar a la nueva situación. En el caso de la Cuenca Hidrográfica del Guadiana se estableció un plazo de tres años para la inscripción de estos derechos en el Registro de aguas temporales o en el Catálogo de aguas privadas, respetando la utilización del mismo a un máximo de cuarenta años en los primeros, y siendo aplicables las normas que regulaban la sobreexplotación del acuífero a todos ellos, es decir, sin exclusividad (López Sanz, 1997, págs. 97-98). El requisito fundamental era la justificación de que el pozo o la captación estaban en uso antes del 1 de enero de 1986.

\section{Resultados: el proceso de inscripción}

Las solicitudes tramitadas durante el periodo de inscripción fueron alrededor de 18.000 para el ámbito de la cuenca hidrográfica. Del total, el 50\% se gestionaron el último día, provocando el colapso en el registro de la administración hidráulica. La premura del proceso hizo pensar que no todos los aprovechamientos fueron registrados (Aragón, 1996). Entre ellos, los de los agricultores que regaban viña y no los declararon porque el riego del cultivo estuvo prohibido hasta 1995. Las solicitudes que no fueron inscritas ni en el Registro, ni en el Catálogo de aguas privadas por incumplimiento de los requisitos requeridos (no poder demostrar que el aprovechamiento existía antes de 1986), iniciaron un proceso de alegaciones que concluyó con la publicación de los reconocimientos definitivos en 1993; el agricultor cuyos derechos no fueron aprobados recurrieron a los Tribunales de Justicia, ocasionando que muchos usuarios no los declararan por no entrometerse en pleitos con la Administración hidráulica (Oñate, 2003, pág. 304).

Según el Inventario de captaciones de 1989, el número de pozos catalogados para la cuenca del Guadiana en Castilla-La Mancha fue de 27.285 (figura 2). Destaca una ostensible densidad desde la parte central de la cuenca hidrográfica hacia la parte nororiental, a través del área de influencia del acuífero de la Mancha Occidental o sistema acuífero 23. Los municipios insertos acaparan el mayor número de pozos reconocidos. Por ejemplo, solamente tres reúnen el 30\% de las captaciones registradas: Daimiel, 
con 2.810 (el 13,6\% del total), Alcázar de San Juan, con 1.805 (8,7\%) y Manzanares con $1.582(7,6 \%)$. Los mismos municipios, más Villarrobledo, ostentan las mayores superficies con derecho a riego. Del total de las 159.568 ha registradas, Alcázar de San Juan contó con 30.433 ha (19\%), Daimiel con 19.199 ha (12\%), Villarrobledo con 10.742 ha (10\%) y Manzanares con $16.429(10 \%)$, acogiendo de forma acumulada casi al $50 \%$ de las extensiones de regadío.

FIGURA 2. SUPERFICIE REGADA POR POZO (1989)
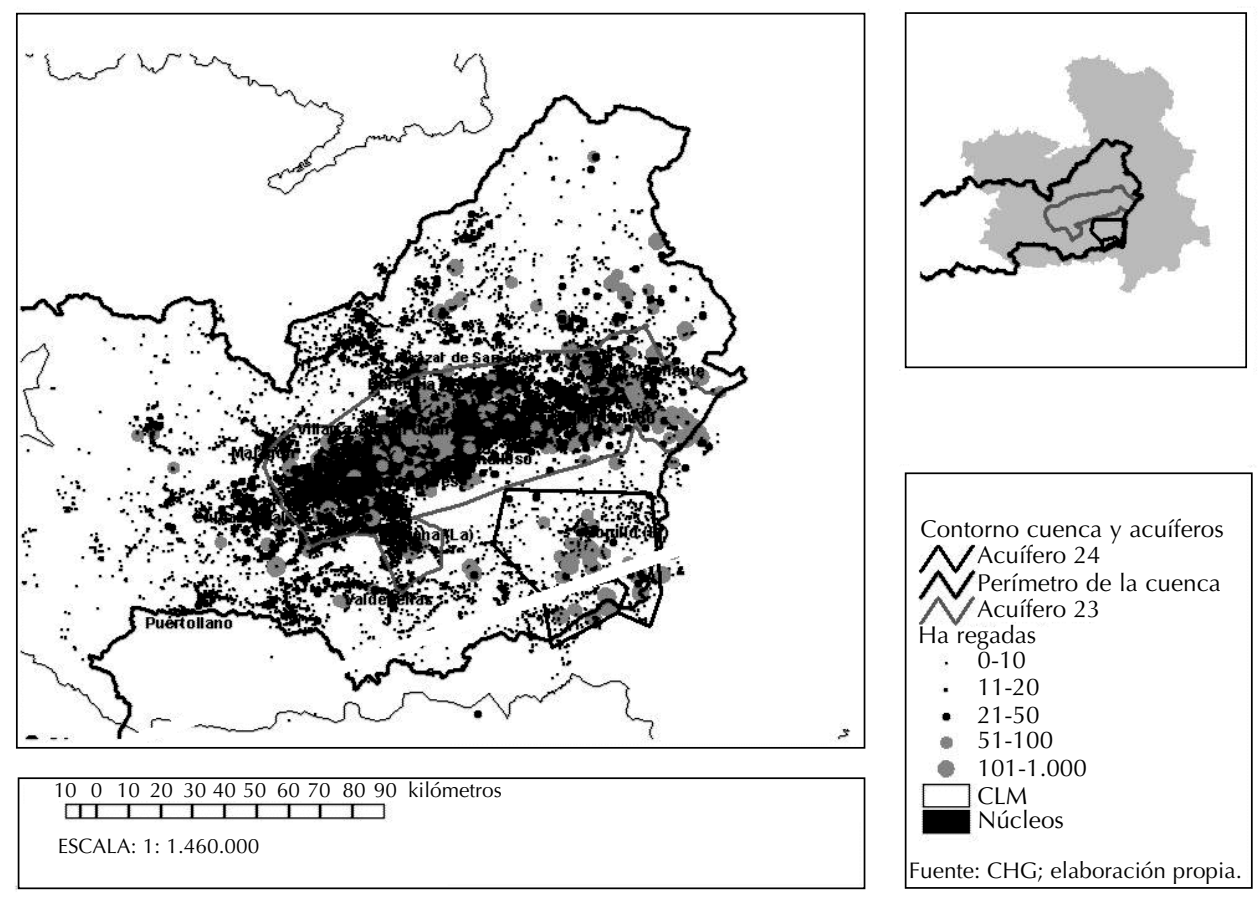

Junto al acuífero de la Mancha occidental, el acuífero 24 o del Campo de Montiel se puede considerar de menor importancia respecto al anterior, debido al menor número de captaciones y de superficie regada, pues albergó poco más de 1.000 ha irrigadas en un modelo agrario basado en el consumo de agua de grandes fincas, siendo, como el sistema acuífero 23, declarados provisionalmente sobreexplotados por el organismo de cuenca en 1987.

El resto de pozos se distribuyen de forma circundante a los cauces fluviales o a otras unidades acuíferas de menor interés. La presencia del dominio paleozoico en la parte occidental explica la inexistencia de captaciones por la naturaleza impermeable de sus materiales, por la ausencia de trasgresión marina durante el Mesozoico, y por el mayor nivel de pendiente. 
La estructura de las captaciones evidencia un predominio de aquellos que son de pequeñas dimensiones (figura 3). El 85,6\% del total no superaron las 10 ha, mientras que tan sólo un 1,7\% rebasó las 50 ha. La significación de este escaso 1,7\% es proporcional al obtenido en el $85 \%$ de las captaciones, porque ambos albergaron alrededor de una cuarta parte del total de las extensiones regadas. El desequilibrio en cuanto a reconocimiento de derechos sería más evidente si añadiésemos el intervalo de más de 20 ha; con éste último, un 6,6\% de los pozos significarían unas 83.400 ha, es decir, un $52,3 \%$ del regadío inventariado.

Figura 3. PorCentaje DE POZOS Y SUPERFICIE REGADA POR INTERVALO (1989)

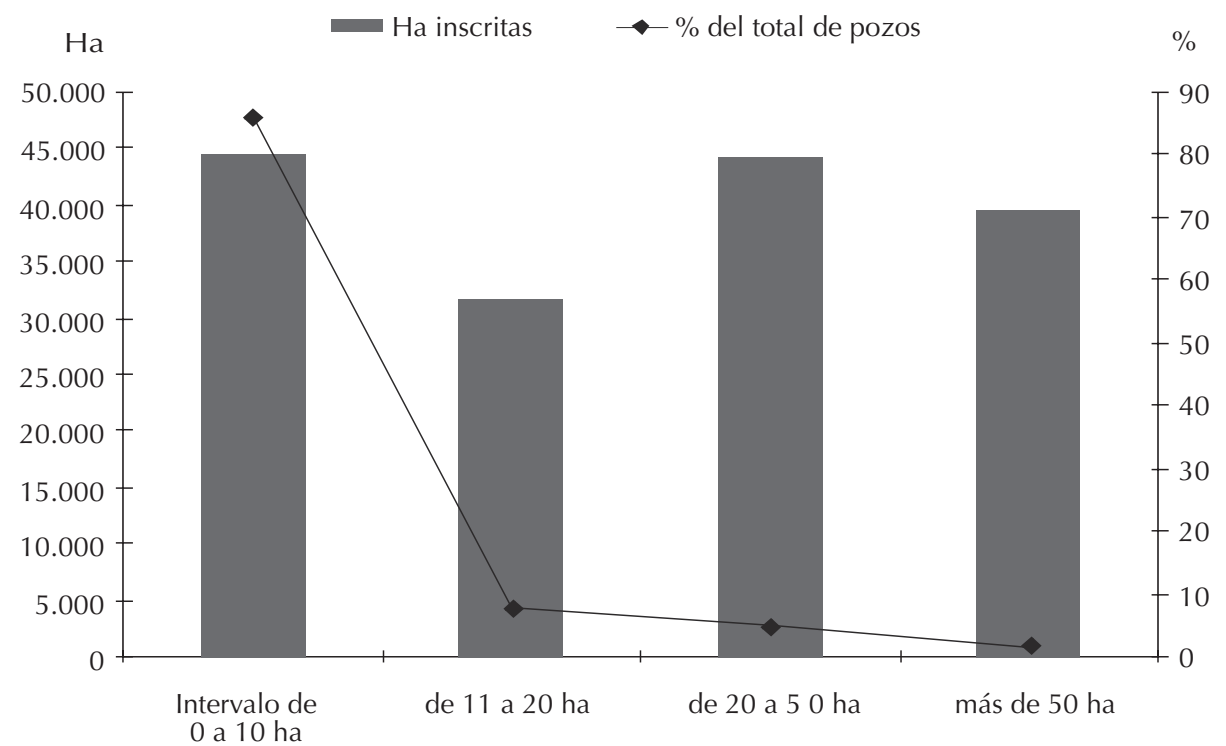

Fuente: C.H.G.; elaboración propia.

En el intervalo de más de 50 ha por captación se contabilizaron 466 pozos, de los que 144 superaron las 100 ha y siete lo hacían por encima de las 250, asentándose en la parte más céntrica del acuífero de la Mancha Occidental, el límite oriental del mismo acuífero con el de la Mancha Oriental, y otras captaciones diseminadas en el acuífero del Campo de Montiel.

La estructura de las captaciones presenta un similar patrón de comportamiento en Alcázar de San Juan, Daimiel, Manzanares y Villarrobledo. De los 7.321 pozos contabilizados en estos municipios, el 3\% se insertan en el 
intervalo de más de 50 ha regadas (226 entre las cuatro localidades), representando la cuarta parte de las superficies de regadío inventariadas (18.688 ha). Alcázar de San Juan es el municipio donde esos desequilibrios son más patentes, ya que tan sólo un $6 \%$ de los pozos representan un tercio de la superficie de riego.

En conclusión, se constataron evidentes desigualdades en el tamaño de los pozos, sobretodo en aquellos lugares con mayor disponibilidad hidrológica. Las mayores captaciones fueron configurándose hacia un tipo de explotación basada en la presencia de cultivos herbáceos en las que el propietario, organizado de forma particular o colectiva, ha constituido empresas agrarias de marcada rentabilidad. Evidentemente, aquellas extracciones que superaron las 50 ha inscritas acogieron a un tipo de propietario con intereses y formas de producción distintas al resto. Los agricultores con sondeos de menor entidad representan a aquellos que, en mayor parte, se dedican profesionalmente a la agricultura, y que son más sensibles a las consecuencias de los periodos de sequía y a las decisiones administrativas.

\section{Acercamiento a los titulares de grandes captaciones}

La significación alcanzada por las captaciones que superan las 50 ha regadas requiere un comentario que permita la identificación y la caracterización de los titulares catastrales que los ostentan, según las consideraciones apuntadas en el epígrafe segundo. El desigual acaparamiento de superficies y la distinta naturaleza jurídica con la que pueden aparecer son dos aspectos que constatan las diferencias entre este tipo de propietarios, según el estudio del Catastro de Rústica. Estas desigualdades intervienen en el aumento de la complejidad social y económica del territorio.

Tras la consulta y el vaciado de información del Libro de Cédulas Catastrales nos quedan un total de 271 titulares que se sitúan por encima del umbral establecido (+50 ha de regadío) en los municipios de referencia. Los resultados son similares a los conseguidos en el Inventario de captaciones y demuestran la trascendencia de estos cuatro municipios en la estructura regada de la cuenca hidrográfica (cuadro 1). Los grandes propietarios no representan más del $2 \%$ del total municipal, aunque presenten entre un tercio y la cuarta parte de las superficies irrigadas de cada municipio, Ilegando incluso al 58,5\% en el caso de Alcázar de San Juan.

En el listado conseguido podemos identificar varios apellidos pertenecientes a la nobleza y a la burguesía local que participaron en las sucesivas compras de tierras desde el final del proceso desamortizador. Entre ellos 
fueron los herederos del Conde de las Cabezuelas (Juan de la Cruz Baíllo y Marañón) los que llevaron un mayor número de compras, sobre todo José Vicente Baíllo, que invirtió cerca de medio millón de reales (Valle, 1995: 192). Las posesiones adquiridas por la nobleza local se han seguido manteniendo o disgregando a lo largo del tiempo, con la incorporación de otros apellidos procedentes de la burguesía y nobleza provinciales, como los Peñalva, los Enríquez de Luna y los Treviño (Pillet, 1989, pág. 136; Esteban, 1991).

Cuadro 1. Principales resultados en los cuatro municipios de referencia. AÑo 2000

\begin{tabular}{lccccc} 
& Titulares* & $\begin{array}{c}\text { Superficie } \\
\text { regada (ha)* }\end{array}$ & \% titulares* & $\begin{array}{c}\text { Regadío total } \\
\text { (ha)** }\end{array}$ & $\begin{array}{c}\% \text { regadío } \\
\text { del total** }\end{array}$ \\
\hline Alcázar de San Juan & 106 & 19.622 & $1,7 \%$ & 33.529 & 58,5 \\
Daimiel & 63 & 6.786 & $1,5 \%$ & 24.300 & 27,9 \\
Manzanares & 56 & 6.259 & $1,3 \%$ & 19.918 & 31,4 \\
Villarrobledo & 46 & 6.681 & $0,9 \%$ & 19.605 & 34,0 \\
\hline
\end{tabular}

Fuente: Elaboración propia.

${ }^{\star}$ C.G.C.C.T.

${ }^{\star}$ Delegaciones de Agricultura JCCM.

Ese escaso número de titulares consiguen una notabilidad sin igual dentro de la estructura agraria, social, económica y ambiental del territorio. Entre las consideraciones de tipo social destacamos el poder de decisión que tienen en las Comunidades de Usuarios, debido a que el sistema de voto se efectúa de forma modulada, es decir, según las hectáreas aportadas por cada uno. De esta manera, cualquier resolución está supeditada al hecho de que los mismos la apoyen o la veten, aun cuando no hubieran asistido a la pertinente Asamblea General por haber utilizado el sistema del voto delegado.

Desde el punto de vista económico, los grandes terratenientes son los máximos beneficiarios del proceso de reconocimiento de los derechos de uso de agua por la Confederación, situándoles en una buena posición de partida de cara a la compra y a la venta de derechos de agua que tiene previsto el Plan Especial del Alto Guadiana. De todas estas premisas se deduce la trascendencia que tiene la regulación, el control y la gestión de las grandes explotaciones de cara a una posible solución al problema de la sobreexplotación, o con vistas a la proyección de marcos de actuación futuros que fomenten la implantación de otro tipo de agricultura más sostenible, o donde impere la justicia social en el reparto del agua. 
De entre los propietarios con más de 50 ha aparecen una serie de titulares de naturaleza colectiva. Las formas de organización que presentan son muy variadas, oscilando entre las Sociedades Agrarias de Transformación, las Sociedades Anónimas, las Comunidades de Bienes, etc. De la significación de unas respecto a otras podemos colegir su comportamiento empresarial, ya que las Sociedades Anónimas necesitan una capitalización previa superior que la de otras figuras, o que en las Sociedades Agrarias de Transformación no exista un mínimo legal de capital previo a imponer, y no sea obligatoria, al igual que las Comunidades de Bienes, su inscripción en el Registro Mercantil.

Los resultados confirman que alrededor de una cuarta parte de los grandes titulares está representado por este tipo de colectivos, significando alrededor de un 15 a un $20 \%$ de las superficies totales de regadío. En algunos municipios como Daimiel o Villarrobledo son los que más regadíos acaparan. En el primer caso, es la SAT Obregón la que reúne 560 ha en las cercanías al Parque Nacional de las Tablas de Daimiel, condicionando que desde varios colectivos ecologistas se apunte la necesidad de la adquisición de parte de los derechos de agua de esta Sociedad a partir de la futura oferta pública que tiene prevista el Plan Especial del Alto Guadiana. Respecto a Villarrobledo, es Deygesa S.L. la que aglutina a un total de 1.159 ha de regadío, siendo de las máximas beneficiarias en la obtención de subvenciones de la PAC según los listados públicos de ayudas recibidas (JCCM, 2001). Existe una similar representación entre Sociedades Agrarias de Transformación, Sociedades Limitadas y Sociedades Anónimas, cada una con alrededor de un $25-28 \%$ del total de este tipo de entidades, mientras que "otras sociedades", es decir, Comunidades de Bienes, Asociaciones, etc. tan sólo presentan un $18 \%$ del total de formas jurídicas.

Aparte de la significación cuantitativa del regadío y de las distintas formas de organización que puedan presentar, el lugar de residencia es un elemento que también ayuda a comprender las relaciones sociales y económicas de un territorio. Es obvio que si predomina una vinculación local de los terratenientes se asegura una cierta reversión de los beneficios en el territorio. Estaríamos hablando de un uso del agua y de sus relaciones con los espacios naturales sin que hubiera contraprestaciones económicas y sociales en las regiones de origen. La influencia de este tipo de relación socioeconómica sería una de las claves para la identificación del grado de subdesarrollo agrario de una región.

Los resultados en los cuatro municipios de referencia aclaran que alrededor de una cuarta parte del regadío total está en manos de titulares con 
un domicilio fiscal foráneo, suponiendo el $66 \%$ de los grandes propietarios. En los municipios donde impera la gran propiedad se atisba un porcentaje menor de titulares pertenecientes a la misma localidad, estando bastante desequilibrado, por ejemplo, en Alcázar de San Juan, con 85 titulares (el $79 \%$ del municipio). Las superficies que acaparan pueden significar entre el 20 y el $45 \%$ de las extensiones regadas municipales, sin contar a los no residentes en el municipio que poseen menos de 50 ha regadas (cuadro 2).

Cuadro 2. Superficie ReGada (ha) SEGún lugar de RESIDENCIA (HA)

\begin{tabular}{|c|c|c|c|c|c|}
\hline Regadío & Municipio & Provincia & Región & Fuera región & $\begin{array}{c}\text { Total } \\
\text { superficie } \\
\text { no municipal }\end{array}$ \\
\hline Alcázar de San Juan & 4.073 & 9.150 & 977 & 5.422 & 15.549 \\
\hline Daimiel & 2.476 & 2.946 & 402 & 963 & 4.311 \\
\hline Manzanares & 2.431 & 1.445 & 0 & 2.383 & 3.828 \\
\hline Villarrobledo & 2.898 & 756 & 132 & 2.895 & 3.783 \\
\hline
\end{tabular}

Fuente: C.G.C.C.T; elaboración propia. Año 2000.

En la interpretación de estos indicadores juega un papel fundamental el grado de desvinculación del propietario, ya que se puede entender desde una perspectiva provincial, regional y nacional, siendo el nivel de extraversión económica distinto. La residencia provincial es la más generalizada, siendo la cercanía geográfica el principal factor explicativo: en Manzanares, es Membrilla su principal contribuyente (hasta 10 titulares), y en Alcázar de San Juan, es Herencia, con diez propietarios también. La superficie es de poco más 14.000 ha en los cinco municipios (un 15\% del total).

De los que residen en Castilla-La Mancha, vuelve a ser Alcázar de San Juan junto a Daimiel los casos más expresivos, con una considerable presencia de localidades insertas dentro de la provincia de Toledo; en cambio, en Villarrobledo, son los próximos territorios de la provincia de Cuenca los que alcanzan el mayor nivel de contribución, situándose en La Almarcha o en Iniesta. La significación de las extensiones es la más discreta de todas las escalas territoriales, con tan sólo un 1,5\% del total del regadío. Por último, los residentes fuera de la región significan el $12 \%$ de las superficies, siendo el ámbito de residencia más importante en Villarrobledo o Daimiel. La Comunidad Autónoma de Madrid es la más registrada en las cédulas catastrales, seguida, muy de lejos, por la Comunidad Valenciana y Cataluña. Alcázar de San Juan ostenta al máximo número de propietarios residentes en la Comunidad de Madrid, con un total de 21 casos. Entre ellos destaca 
una sola titular que comprende 1.464 ha de regadío (un 5\% del total), cuyo apellido (Peñalva) hace referencia a la burguesía provincial.

\section{LOS GRANDES TITULARES Y LA AGRICULTURA DE REGADÍO EN LA ACTUALIDAD}

Desde principios de los años noventa se han producido una serie de circunstancias que han influido de desigual manera en los propietarios de derechos. Las más importantes son la creación de las Comunidades de Regantes, las disposiciones del organismo de cuenca coincidentes en el tiempo con el periodo de sequía, la promulgación de un plan de compensación de rentas entendida dentro de las medidas de acompañamiento de la reforma de la PAC, y por último, las posibles repercusiones de la aplicación de un Plan Especial para el Alto Guadiana.

Las Comunidades de regantes surgen al amparo de la Ley de Aguas de 1985. En el Capítulo IV de la misma se establece la necesidad de constituir comunidades de usuarios que sirvieran de intermediarios entre los mismos y la administración. Se les otorgó el carácter de corporaciones de derecho público adscritos al organismo de cuenca, con una serie de órganos decisorios sobre la gestión del agua de sus territorios. Los objetivos establecidos se dirigían hacia la defensa de los derechos e intereses de los regantes, bajo el principio de velar por el buen funcionamiento u óptimo ordenamiento de los aprovechamientos.

Desde la constitución de la primera comunidad de regantes en 1989, las 20 entidades de aguas subterráneas creadas hasta el día de hoy han sido partícipes de la complejidad social y administrativa que ha envuelto el desarrollo de sus actividades. En algunos casos, las comunidades de regantes no han podido desempeñar óptimamente el papel de intermediarios o el control de la gestión de los acuíferos, debido a factores de tipo legislativo, organizativo y operativo (Hernández, 1998). Entre ellos, los factores operativos son de los más importantes en el devenir de la problemática suscitada, ya que la toma de decisiones y el potencial presupuestario se establecen según el número de comuneros y la superficie que aporta cada miembro. Ello motiva que la disponibilidad de presupuestos sea dispar, y por consiguiente, la de los equipamientos técnicos y económicos que definen ese papel gestor. Por consiguiente, las comunidades de usuarios con mayor número de hectáreas tienen un mayor grado de consolidación, correspondiéndose con aquellos municipios que aglutinan a las captaciones de mayores dimensiones (López Gunn y Hernández, 2001). 
En segundo lugar, entre las disposiciones del organismo de cuenca destacó la sanción de un régimen de explotación anual que fijaba el volumen máximo de agua a utilizar. Los regímenes que se publicaron en los años de sequía (1991-1995) fueron de duro cumplimiento para el agricultor, afectando sobretodo a los pequeños propietarios. Las grandes propiedades han seguido empleando el mismo peonaje año tras año en diferentes modelos de aprovechamiento (arrendamiento, etc.), mientras que el pequeño agricultor vio como su actividad tuvo un riesgo evidente de no continuidad. Los medianos y los grandes propietarios han sido los más beneficiados por las disposiciones que se pusieron en marcha para compensar los efectos perniciosos de estos regímenes de explotación (López Sanz, 1997).

El más significativo fue la promulgación de un programa agroambiental conocido Plan de Compensación de Rentas. En el mismo se ofrecía un pago compensatorio según el consumo de agua que se quisiera reducir por explotación, siendo del 50, 70 o del 100\%. El agricultor se comprometía al cumplimiento de diferentes obligaciones ambientales, entre las que figuraban la elaboración de un plan de cultivos anual o el respeto hacia las buenas prácticas agrarias. Con su puesta en funcionamiento se invitaba a que los agricultores cumplieran con las disposiciones del organismo de cuenca, y se redujera, en la medida de lo posible, el fraude que se hacía al mismo, sobretodo por aquellos que realizaron fuertes inversiones en sus explotaciones y que tenían ahora un uso muy limitado del agua (Romero y Martínez Vega, 1997; López Sanz, 1998; Viladomiú y Rosell, 1997, pág. 25). El alcance ecológico, social y económico del Plan de Compensación ha sido cuestionado y debatido hasta su no prorrogación en 2002. Entre otras cuestiones, se apunta el retraso con el que se ha aprobado por el aparente desconocimiento del funcionamiento de la Unidad Hidrológica, la problemática que hace referencia a la formación o a la asistencia al agricultor, las medidas a seguir con los pozos ilegales o las acciones a emprender cuando termine el programa (López Sanz, 1998, págs. 236-242; Cruces de Abia y Martínez Cortina, 2000, pág. 58).

No obstante, también podemos añadir efectos positivos, como la reducción del consumo de agua y la rentabilidad de las explotaciones agrarias al sumarle los pagos compensatorios de la PAC. Éste es quizá uno de los aspectos más novedosos porque muchos propietarios han podido percibir subvenciones por estas dos vías. La coincidencia de ambos pagos posibilitó la obtención de una alta rentabilidad económica de la explotación, incrementada por la subida de los precios de aquellos cultivos exigentes en agua en época de sequía. De esta manera se pudieron conseguir unos 
importantes beneficios por partida triple: por las ayudas directas de la PAC; por el Plan de Compensación de Rentas; y por la subida de los precios de los cultivos con alta necesidad hídrica en épocas de sequía.

\section{El Plan Especial para el Alto Guadiana (PEAG)}

El Plan Hidrológico Nacional de 2001 estipulaba, en su disposición adicional cuarta, la necesidad de aprobar un Plan especial para el Alto Guadiana que resolviera el problema ambiental de los acuíferos subterráneos. Se presentó una primera versión en febrero de 2004 que fue muy contestada por diversos actores sociales y económicos regionales en el proceso de alegaciones. Entre las principales reivindicaciones figuró la falta de participación en la redacción del texto, la posible falta de adecuación a la realidad de los objetivos o de las medidas planteadas, y la ausencia de Evaluación de Impacto Ambiental del Plan (Ruiz, 2007, págs. 203-204).

Los cambios políticos acaecidos en marzo de 2004 hicieron sospechar que el PEAG no seguiría adelante, sin menoscabo de la finalización del proceso de alegaciones a primeros de abril. El cese del Presidente de la Confederación Hidrográfica del Guadiana (CHG) confirmó que se tendría que volver a elaborar un nuevo texto. Las diferentes reuniones que se celebraron en julio de 2004 entre el Presidente de la CHG y otras instituciones como la Administración local o la Consejería de Obras Públicas dejaron claro el interés en la nueva redacción de un nuevo borrador del PEAG que saliera adelante lo más consensuado posible, teniendo en cuenta las 63 alegaciones presentadas al mismo.

El actual Plan Especial del Alto Guadiana se aprobó por el Real Decreto 13/2008 de 11 de enero, donde se recoge el objeto, el ámbito territorial, la aplicación temporal, y las funciones de los órganos que van a coordinar, impulsar y gestionar el Plan. Las medidas que se establecen se organizan a partir de un programa de actuaciones generales y otras de acompañamiento. Las primeras tratan las medidas para la reordenación de los derechos de usos del agua y la modificación del régimen de explotación de los pozos existentes.

La reordenación de los derechos tienen como finalidad la conversión de los derechos privados en concesionales, con el fin de que puedan ser cedidos entre particulares, y también a que se pueda acceder a su compra por parte de un Centro de Intercambio de Derechos (CID) con el propósito de destinarlos a la recuperación del acuífero de la Mancha Occidental. En principio, la venta se realizaría de forma totalmente voluntaria, fijándose un 
precio que rondaría los 6.000 euros por hectárea. Del volumen rescatado se tiene pensado destinar un $70 \%$ a la recuperación ambiental, y el 30\% restante a la Comunidad Autónoma que implantará las líneas estratégicas para su uso. La gestión de ese 30\% corre a cargo de un Consorcio de gestión que dotará de nuevas concesiones a aquellas explotaciones que cumplan con unos requisitos, como la generación de empleo, la proximidad o no a un espacio natural protegido, y la no superación de un determinado tamaño.

En la modificación del régimen de explotación de los pozos se indica los requisitos que deben cumplir los titulares para acceder a la misma, indicando la denegación de solicitudes en el caso de que se trate de reprofundizaciones, ampliaciones, incremento del consumo, cambio de ubicación y afección a espacios naturales.

Las medidas de acompañamiento se enuncian a partir de varios programas: Programa hidrológico; Programa de apoyo a las Comunidades de regantes; Programa ambiental; Programa de información y sensibilización ambiental; Programa de abastecimiento y depuración de aguas; Programa de reconversión socioeconómica; y Programa de medidas agrarias. Los más importantes son el Programa Hidrológico, el Programa Ambiental y el Programa de medidas agrarias.

El Programa Hidrológico desarrolla las herramientas necesarias para la gestión hídrica, entre los que se encuentran los sistemas de información integrados, los dispositivos de vigilancia y control, las herramientas de participación e información pública, y el funcionamiento del Centro de Intercambio de Derechos y del Consorcio.

El Programa Ambiental plantea la conservación del medio natural en concordancia con lo establecido en distintos preceptos que abogan por la conservación, como la Directiva Marco de Aguas (DMA), la Red Natura 2000 o la Ley de Espacios Naturales Protegidos, a partir de una serie de actuaciones encaminadas a restaurar los ecosistemas, reducir la contaminación, y divulgar los valores ambientales de los humedales de la cuenca alta.

El Programa de medidas agrarias se complementa con el futuro Plan de Desarrollo Rural Sostenible, estableciendo ayudas a políticas agrarias sectoriales, ayudas, mediante su correspondiente medida agroambiental, para la implantación de cultivos agroenergéticos, y fomento de la agricultura de secano extensivo en aquellas explotaciones que se hayan acogido a la venta total de sus derechos. Estas actuaciones, se entienden dentro de una necesaria transformación del modelo agrícola, en la que la aportación del presupuesto del Fondo Europeo Agrícola de Desarrollo Rural (FEADER) se hace fundamental. 
La interrelación de todas las iniciativas intenta limitar las extracciones de agua para regadío a unos $200 \mathrm{hm}^{3}$ al año, lo que repercutiría en la mejora de los niveles piezométricos del acuífero. El documento apunta el cumplimiento de los objetivos cuando el volumen anual medio de salidas hacia el Parque Nacional de Las Tablas de Daimiel sea de unos $30 \mathrm{hm}^{3}$, lo que facilitaría cumplir con los compromisos propuestos por la Directiva Marco del Agua.

\section{CONSIDERACIONES FINALES: PROPUESTAS DE ACTUACIÓN}

Para que el PEAG alcance sus objetivos es necesario revertir algunas inercias del actual modelo agrario y que exista una clara voluntad de las administraciones para ejecutarlo. La consideración del regadío como factor indispensable para el desarrollo agrario, el mantenimiento de la superficie regada actual, y la pasividad legal ante las más de 40.000 captaciones ilegales son contrariedades que están jugando a la contra. Sin embargo, otras cuestiones como su adecuación a la DMA, el óptimo proceso de participación pública, el alto grado de consenso alcanzado, y la coordinación entre las administraciones, pueden llevarnos a un cierto optimismo, siendo a medio y largo plazo cuando seamos capaces de determinar su éxito

Los resultados del Inventario de captaciones y del Catastro de Rústica evidencian un reparto social del agua injusto, dentro de un statu quo que consolida y apoya a los grandes propietarios. Los mecanismos de intervención de las administraciones deben priorizar y comprender esta problemática, discerniendo el papel que desempeña la agricultura familiar respecto a otros negocios agrarios que no revierten en el territorio. Es necesario que el organismo de cuenca ajuste una serie de medidas que beneficien, bajo un principio de solidaridad, a la mayoría de los agricultores que utilizan el agua como único medio para el sustento de sus familias, y limitar, en la medida de lo posible, aquellos usos cuyo objetivo principal sea la especulación o el beneficio empresarial que no revierte en el territorio. Entre las disposiciones que pueden articular el proceso figura el Régimen de Explotación, que en su reparto en módulos escalonados podría ser más beneficioso para los pequeños y medianos agricultores; la adquisición y reordenación de derechos que plantea el Plan Especial siempre y cuando se realice sobre circunstancias y objetivos reales; y el reconocimiento, por parte del Consorcio del PEAG, de nuevas concesiones a explotaciones que rieguen cultivos sociales y que cumplan con los requisitos establecidos. 
Un modelo agrario tan dependiente del uso del agua y del acceso que se tiene a la misma muestra síntomas de agotamiento porque carece de unos principios de proyección futuros, tanto desde el punto de vista económico, porque no se reparte equitativamente la riqueza ni se obtiene más beneficio de una agricultura excedentaria; como del ecológico, por la escasez y el riesgo de agotamiento definitivo del agua. Por tanto, es ineludible plantearnos qué tipo de agricultura estamos dispuestos a seguir. Si el modelo está agotado, habría que plantear otros alternativos. Es necesario un nuevo tipo de agricultura que incentive la calidad frente a la cantidad, que contemple un reparto más justo del agua, que comprenda, dentro de este contexto, las ventajas de la agricultura de secano, que se adapte a los nuevos procesos de diversificación económica en el medio rural, que respete los modos de producción ecológicos, y que en definitiva, se conciencie de las distintas utilidades que puede tener el agua dentro del proceso de diversificación económica que plantean los programas de desarrollo rural, muy alejadas de otras iniciativas claramente incompatibles con la identidad ecológica y cultural del territorio.

\section{Conclusiones}

El reconocimiento de derechos sobre el uso del agua subterránea derivados de la Disposición Adicional Tercera y Cuarta de la Ley de Aguas de 1985 originó una seria conflictividad social en el Alto Guadiana, que al menos se puede constatar desde dos puntos de vista: primero, por la existencia de dos modelos de explotación que cuentan con distinta capacidad de adaptación ante las medidas administrativas y la situación económica (el familiar y el empresarial); y segundo, por la ventaja comparativa que supone poder contar con una concesión administrativa de agua en un acuífero sobreexplotado, entre las que destacan su consideración como interlocutores necesarios con la Administración, la posibilidad de disfrute de programas agroambientales, (como ocurrió con el Plan de Compensación de Rentas), y una capacidad de adecuación más flexible a otras disposiciones agrarias, como ha acontecido con los programas de reconversión y de reestructuración del viñedo sancionados por la Junta de Comunidades de CastiIla-La Mancha desde el año 2000.

Recibido 16.05.06

Aceptado 30.7.08 


\section{BIBLIOGRAFÍA}

Aragón, J. R. (1996): Informe sobre el proceso de inscripción de aguas de los derechos de aguas privadas para uso de riego a que se refieren las disposiciones transitorias tercera y cuarta de la Ley de Aguas de 2 de agosto de 1985, Comisaría de aguas, Confederación Hidrográfica del Guadiana, Ciudad Real.

Arroyo, F. (1988): "Innovación agraria y estatuto regional en Castilla-La Mancha", en Pillet, F. (coord), El espacio rural de Castilla-La Mancha. II Reunión de Estudios Regionales de Castilla-La Mancha. Tomo I, Diputación de Ciudad Real, Ciudad Real, pp. 143-166.

Arroyo, F. (1998): Agua, paisaje y sociedad en las Relaciones Topográficas de Felipe II, Ediciones del Umbral, Madrid.

Casabianca, F. (1998): "Política comunitaria y ordenación del territorio. Necesidad de una adaptación de la PAC al contexto mediterráneo", Anales de Geografía de la Universidad Complutense, $\mathrm{n}^{\circ}$ 18, Universidad Complutense de Madrid, pp. 37-46.

Cebrián, A. (1988): "Evolución y distribución del regadío en la Comunidad Autónoma de Castilla-La Mancha", en Pillet, F. (coord), El espacio rural de Castilla-La Mancha. II Reunión de Estudios Regionales de Castilla-La Mancha. Tomo I, Diputación de Ciudad Real, Ciudad Real, pp. 193-201.

COAG-IR (2004): Propuestas sociales para el Plan Especial del Alto Guadiana, Presentación Power Point Multimedia, Coordinadora Agraria y Ganadera. Iniciativa Rural, Daimiel.

Coleto, C.; Martínez Cortina, L. y Llamas, R. (eds.) (2002): Conflictos entre el desarrollo de las aguas subterráneas y la conservación de los humedales de la cuenca alta del Guadiana, Fundación Marcelino Botín, Madrid.

Confederación Hidrográfica del Guadiana (2003): Plan especial del Alto Guadiana, MIMAM, Ciudad Real.

Cruces de Abia, J. et al. (coords.) (1998): De la noria a la bomba. Conflictos sociales y ambientales en la cuenca alta del río Guadiana, Ed. Bakeaz, Bilbao.

Cruces de Abia, J. y Martínez Cortina, L. (2000): La Mancha húmeda. Explotación intensiva de las aguas subterráneas en la cuenca alta del río Guadiana, Fundación Marcelino Botín, Papeles del proyecto de aguas subterráneas, Madrid.

Esteban, L. E. (1991): Agricultura y ganadería en Ciudad Real en los siglos XIX y XX, Diputación Provincial de Ciudad Real, Ciudad Real.

Fayas, J. A. (2000): "La gestión de las aguas subterráneas", O.P. Revista del Colegio de Ingenieros de Caminos, Canales y Puertos de Barcelona, $n^{\circ}$ 51, vol. 2.

García, J. (1989): "Configuración del regadío en las Ilanuras castellanas", Los paisajes del agua. Libro jubilar dedicado al profesor Antonio López Gómez, Universidad de Valencia y Universidad de Alicante, Valencia, pp.121-132.

Hernández, N. (1998): “El papel de los usuarios en la gestión del agua en el acuífero de la Mancha occidental: oportunidades ante una situación de conflicto y carestía", I Congreso Ibérico sobre Planificación y Gestión de Aguas, Zaragoza, pp. 1-8.

Hernández, N. y Llamas, R. (2001): La economía del agua subterránea y su gestión colectiva, Fundación Marcelino Botín, Ed. Mundi-Prensa, Madrid.

Hernández, N. y López-Gunn, E. (2003): "La gestión colectiva de las aguas subterráneas en La Mancha", en Coleto, C.; Martínez Cortina, L. y Llamas, R. (eds), Conflictos entre el desarrollo de las aguas subterráneas y la conservación de los humedales: la cuenca alta del Guadiana, Fundación Marcelino Botín, Ed. Mundi-Prensa, Madrid, pp. 291-324.

Hervás, J. L. (1991): "El Guadiana" en AL-MUDAYNA (1991): historia de los regadíos en España (...a.C.-1931), MAPYA, Madrid, pp. 173-246.

JCCM (2001): Pagos de los FEOGA-Garantía realizados el año 2001, en: www.jccm.es/agri$\mathrm{cul} /$ paginas/agricultura-ganadería/pagos2001.htm

Juárez, C. (1979): Caracteres climáticos de la cuenca del Guadiana y sus repercusiones agrarias, Universidad de Salamanca, Salamanca. 
López-Gunn, E. y Hernández, N. (2001): "La gestión colectiva de las aguas subterráneas en La Mancha: análisis comparativo", La economía del agua subterránea y su gestión colectiva, Fundación Marcelino Botín. Ed Mundi-Prensa, Madrid, pp. 405-473.

López-Gunn, E. (2002): "La participación de los usuarios y de los ciudadanos en la gestión de las aguas subterráneas: el caso de Castilla-La Mancha", Jornadas sobre presente y futuro del agua subterránea en España y la Directiva Marco Europea, Zaragoza.

López Sanz, G. (1997): La gestión del agua subterránea en la cuenca alta del río Guadiana: de la confrontación a la cooperación, Diputación Provincial de Ciudad Real, Ciudad Real.

López Sanz, G. (1998): "De la competición a la cooperación: el marco social, político y económico", en Cruces de Abia, J. et al. (coords.), De la noria a la bomba. Conflictos sociales y ambientales en la cuenca alta del río Guadiana, Ed, Bakeaz, Bilbao, pp. 203-273.

Llamas, R. et al. (1996): "El desarrollo sostenible de la cuenca alta del río Guadiana: aspectos socioeconómicos y ecológicos", RETEMA (Medio Ambiente), septiembre-octubre 1996, pp. 66-74.

Martínez Gil, J. (coord.) (2004): Una nueva cultura del agua para el Guadiana. Desde Ruidera a Ayamonte, Fundación Nueva Cultura del Agua, ADENEX, Zaragoza.

Martínez Santos, P. (2004): Aspectos económicos del nuevo Plan Especial del alto Guadiana: revisión crítica, Trabajo del programa de doctorado de Ciencias Geológicas, Universidad Complutense de Madrid.

Martínez Vega, J. et al. (1995): “Repercusiones de la sobreexplotación de acuíferos y de la P.A.C. en la sustentabilidad de la agricultura manchega", Estudios Geográficos, nº 219, pp. 337-370.

Mata, R. (1988): "La distribución de la propiedad y de la explotación de la tierra en CastillaLa Mancha: aspectos de la situación actual y de su dinámica reciente", en Pillet, F. (coord.), El espacio rural de Castilla-La Mancha. II Reunión de Estudios Regionales de Castilla-La Mancha. Tomo II, Diputación de Ciudad Real, Ciudad Real, pp.165-206.

Oñate, J. M. (2004): "El acuífero 23: perspectivas de un regante", en Martínez Gil, F. (coord.), Una nueva cultura del agua para el Guadiana. Desde Ruidera a Ayamonte, Fundación Nueva Cultura del Agua, ADENEX, Zaragoza, pp. 303-310.

Pillet, F. (1989): "Los regadíos de Castilla-La Mancha: implicaciones actuales y tipos de explotación", Los paisajes del agua. Libro jubilar dedicado al profesor Antonio López Gómez, Universidad de Valencia y Universidad de Alicante, Valencia, pp.133-143.

Pillet, F. (2001): La Mancha. Transformaciones de un espacio rural, Celeste Ediciones, Madrid.

Pillet, F. (coord.) (2007): Geografía de Castilla-La Mancha, Biblioteca Añil ALMUD Ediciones de Castilla-La Mancha, Ciudad Real.

Plaza, J. y Ruiz, A. R. (2002): "Paisaje agrario y regadío: una propuesta metodológica para su tipificación a nivel de cuenca hidrográfica", XX Congreso Nacional de Riegos y Drenajes, AERYD, Ciudad Real, pp. 199-201.

Romero, R. y Martínez Vega, J. (1997): “Transformaciones de uso y estructuras agrarias en la Mancha Occidental", Estudios Geográficos, n² 228, pp. 451-475.

Ruiz, A. R (2007): Tipología territorial de la agricultura de regadío en los municipios de la cuenca hidrográfica del Guadiana, Consejo Económico y Social de Castilla-La Mancha, Toledo.

Serna, J. y Gaviria, M. (1995): La quimera del agua. Presente y futuro de Daimiel y la Mancha Occidental, Siglo XXI, Madrid.

Ureña, F. (1997): "Análisis de la evolución del regadío en la provincia de Ciudad Real en el periodo 1960-1995", III Congreso Nacional de Medio Ambiente, Ministerio de Medio Ambiente, Madrid, pp. 656-668.

Valle, A. R. (1995): La desamortización eclesiástica en la provincia de Ciudad Real (18361854), Servicio de Publicaciones de la Universidad de Castilla-La Mancha, Cuenca.

Velasco, M. (2005): Cien años en el desarrollo de la cuenca alta del Guadiana (1898-1998), Consejo Económico y Social de Castilla-La Mancha, Toledo. 
Viladomiu, L. y Rosell, J. (1997): Informe preliminar sobre el Plan de Compensación de Rentas en los regadíos de la Mancha Occidental y Campo de Montiel (Programa de humedales de las Tablas de Daimiel), Universitat de Barcelona, Barcelona.

\title{
Resumen
}

La apropiación de derechos privados sobre el uso del agua se debe a factores de tipo histórico y económico, siendo delimitados y reconocidos tras la aplicación de la legislación vigente a finales del siglo XX. La comprensión de las consecuencias sociales y económicas que se derivan permite establecer marcos de referencia globales para el enjuiciamiento del problema ambiental que se plantea en territorios con problemas de desarrollo agrario sostenible, tal y como ha ocurrido con la cuenca alta del Guadiana.

Palabras clave: regadíos; propiedad; pozos; conflictividad social; desarrollo sostenible.

\begin{abstract}
The appropriation of private rights on the use of the water owes to factors of historical and economic type, being delimited and being recognized after the application of the effective legislation at the end of century $X^{\text {th }}$. The understanding of the social and economic consequences that are derived allows to establishing global frames of reference for the judgment of the environmental problem that considers in territories with problems of sustainable agrarian development, as it has happened with the Guadiana river high basin.
\end{abstract}

Key words: irrigations; property; wells; social conflict; sustainable development. 